\title{
Reaction Mechanisms of Metals with Hydrogen Sulfide and Thiols in Model Wine. Part 1: Copper Catalyzed Oxidation.
}

Gal Y. Kreitman ${ }^{\dagger}$, John C. Danilewicz ${ }^{\S}$, David. W. Jeffery ${ }^{\ddagger}$, Ryan J. Elias ${ }^{*, \dagger}$

${ }^{\dagger}$ Department of Food Science, The Pennsylvania State University, University Park, Pennsylvania 16802, United States

$\S 44$ Sandwich Road, Ash, Canterbury, Kent CT3 2AF, United Kingdom

* School of Agriculture, Food and Wine, Waite Research Institute, The University of Adelaide, PMB 1, Glen Osmond, South Australia 5064, Australia

* To whom correspondence should be addressed.

Tel: +1 (814) 865-5371

Fax: +1 (814) 863-6132

E-mail: elias@psu.edu 


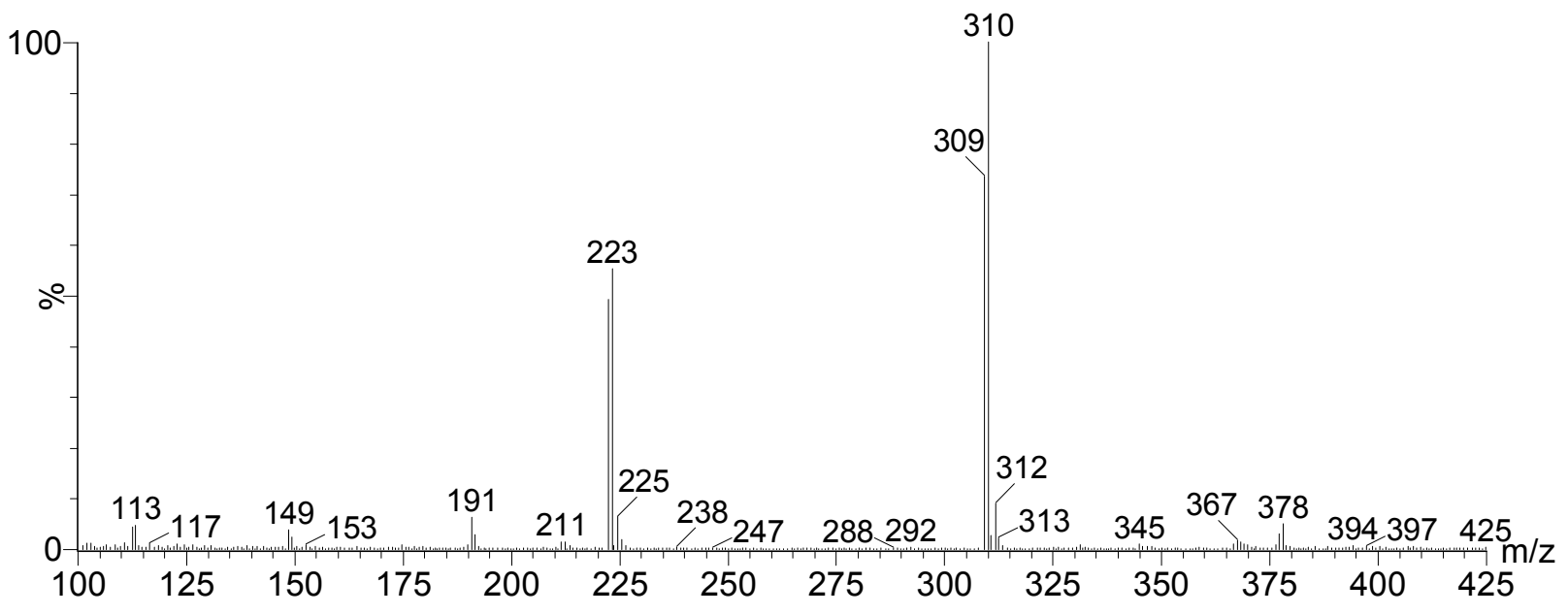

Figure S1: Fragmentation pattern of Cys-bimane. 


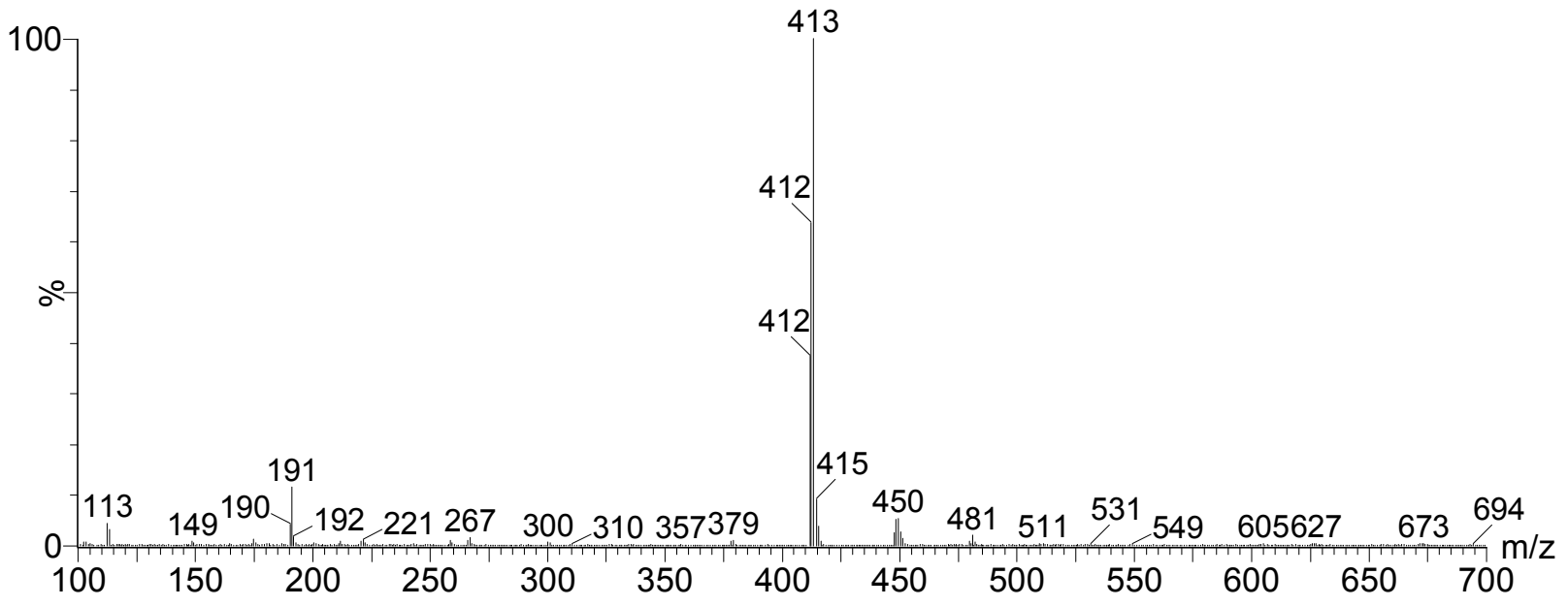

Figures S2: Fragmentation pattern of sulfide-dibimane. 


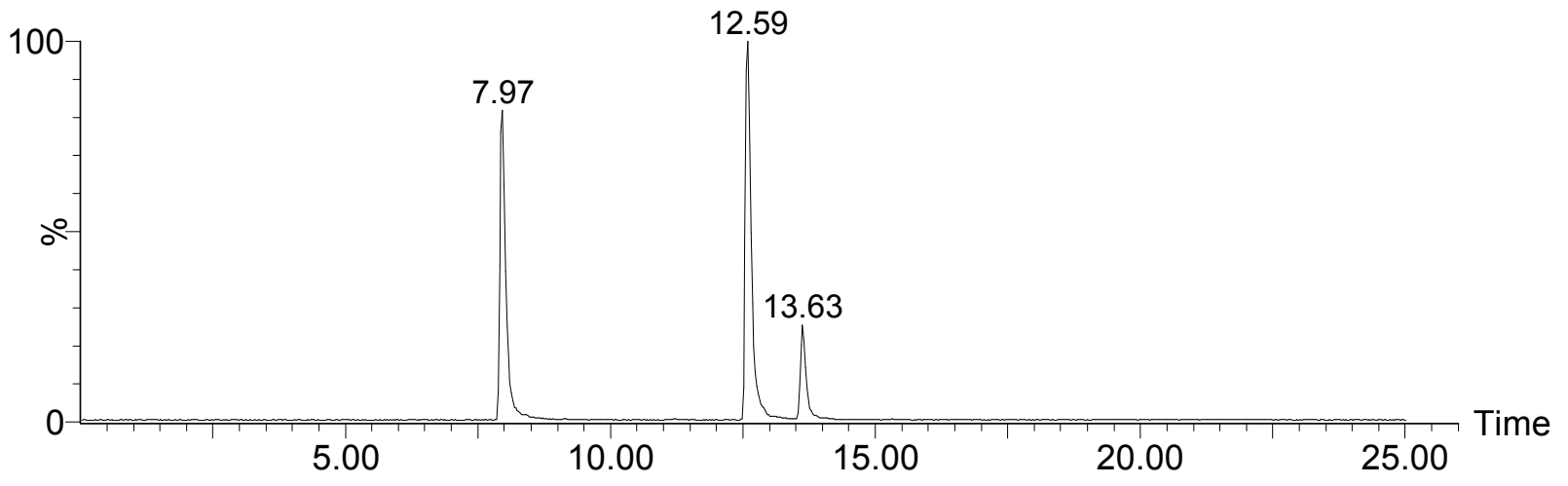

Figure S3: Chromatographic profile of combined MRM spectra. Rt $7.97 \mathrm{~min}-$ Cys-bimane $(\mathrm{m} / \mathrm{z}$ $310 \rightarrow 223) ; 12.59 \mathrm{~min}$ - sulfide-dibimane $(\mathrm{m} / \mathrm{z} 413 \rightarrow 191) ; 13.63 \mathrm{~min}-6 \mathrm{SH}$-bimane $(\mathrm{m} / \mathrm{z}$ $323 \rightarrow 222$ ). 